\title{
AuraGain $^{\mathrm{TM}}$ and $\mathrm{i}-\mathrm{Gel}{ }^{\circledR}$ laryngeal masks in general anesthesia for laparoscopic cholecystectomy
}

\section{Performance characteristics and effects on hemodynamics}

Ulku Sabuncu, MD, Hatice S. Kusderci, MD, Mesut Oterkus, MD, Ruslan Abdullayev, MD, Asli Demir, MD, Oznur Uludag, MD, Sabri Ozdas, MD, Mustafa Goksu, MD.

\section{ABSTRACT}

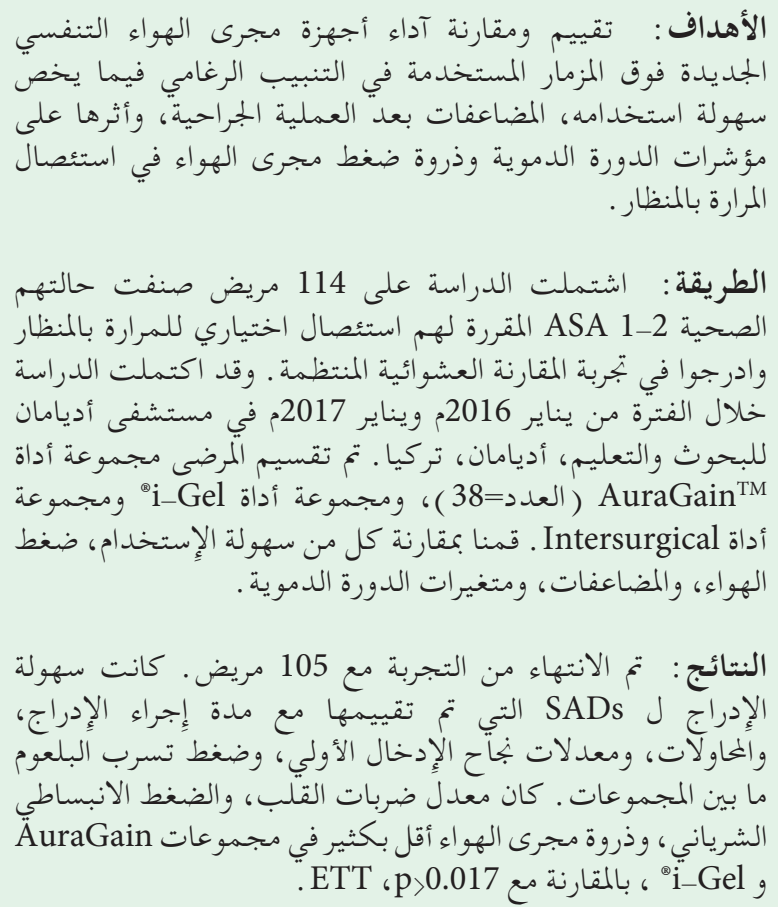

الخاتمة: كل من i-Gel

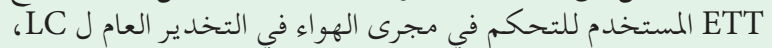

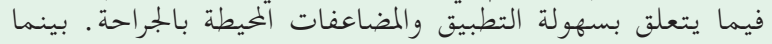

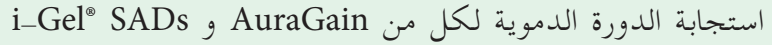

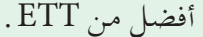

Objectives: To evaluate and compare the performances of new types of supraglottic airway devices (SADs) with endotracheal intubation regarding their ease of insertions, perioperative complications, and effects on hemodynamic parameters and peak airway pressures in laparascopic cholecystectomy (LC).

Methods: One hundred and fourteen patients with ASA 1-2 physical status scheduled for elective LC were recruited for this prospective randomized controlled trial. The study was completed between January 2016 and January 2017 in Adiyaman University Research and Educational Hospital, Adiyaman, Turkey. The patients were divided into AuraGain ${ }^{\mathrm{TM}}$ (Ambu, Ballerup, Denmark) $\quad(\mathrm{n}=38), \quad \mathrm{i}-\mathrm{Gel}^{\circ} \quad$ (Intersurgical Ltd, UK) $(n=35)$, and endotracheal tube (ETT) $(n=32)$ groups. Ease of insertion, airway pressures, complications, and hemodynamic variables were compared.

Results: The trial was completed with 105 patients. Ease of insertion for SADs which was evaluated with insertion procedure duration, attempts, first insertion success rates, and oropharyngeal leak pressures were similar between the groups. Heart rate, systolic and diastolic arterial pressures, and peak airway pressures were significantly lower in the AuraGain and $\mathrm{i}-\mathrm{Gel}^{\circ}$ groups, compared with the ETT, $p<0.017$.

Conclusion: Both AuraGain and $\mathrm{i}-\mathrm{Gel}^{\circ} \mathrm{SADs}$ are comparable with ETT used for airway control in general anesthesia for LC, regarding application ease and perioperative complications. Favorable hemodynamic responses to AuraGain and i-Gel ${ }^{\circ}$ SADs may put them in a better place than ETT.

Saudi Med J 2018; Vol. 39 (11): 1082-1089 doi: 10.15537/smj.2018.11.22346

From the Department of Anesthesiology and Reanimation (Sabuncu, Demir), Yuksek Ihtisas Research and Educational Hospital, Health Sciences University, Ankara, from the Department of Anesthesiology and Reanimation (Kusderci, Oterkus, Abdullayev, Uludag), and from the Department of General Surgery (Ozdas, Goksu), Adiyaman University Research and Educational Hospital, Adiyaman, Turkey.

Received 6th May 2018. Accepted 26th September 2018

Address correspondence and reprint request to: Dr. Ulku Sabuncu, Department of Anesthesiology and Reanimation, Yuksek Ihtisas Research and Educational Hospital, Health Sciences University, Ankara, Turkey. E-mail: sabuncuulku@gmail.com

ORCID ID: orcid.org/0000-0003-3655-3366 
T he most preferred anesthetic technique in laparoscopic cholecystectomy (LC) is general anesthesia with controlled ventilation, most often via endotracheal tube (ETT). However, during the procedure, high intra-abdominal pressures due to carbon dioxide insufflation may increase the risk of passive gastroesophageal regurgitation and carbon dioxide retention. For these reasons, cuffed ETT is the most preferred technique when considered in terms of safety. ${ }^{1}$ The laryngeal mask airway (LMA) is a supraglottic airway device (SAD) developed by Dr Archie Brain, a British anesthesiologist, and it has been in clinical use since 1988. It is used as a convenient alternative to ETT, with easy and atraumatic insertion, as well as minimal somatic and autonomic responses in many clinical conditions. ${ }^{2}$ However, SADs have some disadvantages, like limited protection of the airway from gastric contents. ${ }^{2}$ The second generation SADs can overcome this issue. One of these is the $\mathrm{i}-\mathrm{Gel}^{\circ}$ (Intersurgical Ltd., UK), which is made of medical grade thermoplastic elastomer (styrene ethylenebutadiene styrene) and does not require an inflating cuff. Its design provides a perilaryngeal seal without cuff inflation. In addition, it is easily and rapidly placed, with a reduced risk of pharyngeal tissue compression. Moreover, it has a gastric drainage tube, and it allows the insertion of a gastric tube (maximum $14 \mathrm{Fr}$ ) and aspiration of the gastric contents and air. The third-generation SAD is the AuraGain ${ }^{\mathrm{TM}}$ (Ambu, Ballerup, Denmark), which has an anatomically curved design. Its design allows a rapid establishment of a safe airway. It also has a gastric drainage tube with a low frictional inner surface; thus, making placement of the tube easier (maximum recommended gastric tube is 14 to $16 \mathrm{Fr}$ ).

There have been studies that investigated the performances of ProSeal ${ }^{\mathrm{TM}}$ LMA (Intavent Orthofix, Maidenhead, UK) in LC. ${ }^{3,4}$ However, the performances of $\mathrm{i}-\mathrm{Gel}^{\oplus}$ and AuraGain have not yet been sufficiently investigated. This study aims to evaluate the performances of new types of SADs (AuraGain and i-Gel ${ }^{\oplus}$ ) with endotracheal intubation and compare their ease of insertion, airway pressures, and perioperative complications with ETT. In addition, the secondary aim of the study is to characterise their effects on hemodynamic parameters and peak airway pressures.

Disclosure. Authors have no conflict of interests, and the work was not supported or funded by any drug company.
Methods. Approval for this study was received from the Local Ethics Committee (Inonu University Clinical Research Ethics Committee, Malatya; protocol number 2015/178). Following the ClinicalTrials. gov registration with number NCT02925598 and according to the ethical standards of the Declaration of Helsinki, 114 patients with American Society of Anesthesiologists (ASA) 1-2 physical status scheduled for elective LC were recruited for this prospective randomized controlled trial. The closed envelope method was used for the patient assignment, and patients were divided into 3 groups by a blind anesthesia specialist in the premedication unit, namely the AuraGain, i-Gel ${ }^{\oplus}$, and ETT groups, each with 38 patients. The airway management was determined by a sealed envelope, and the anesthetist in the operating room opened the envelope in which the airway device was determined. Patients who were under the age of 18 or had a history of hiatus hernia, gastroesophageal reflux, body mass index $(\mathrm{BMI})>30 \mathrm{~kg} \mathrm{~m}^{-2}$ or ASA physical status 3 or over and patients who met the difficult intubation criteria were excluded from the study. Written informed consent was obtained from each patient. All the patients were blinded and premedicated with intravenous (IV) metoclopramide (anti-nausea $10 \mathrm{mg}$, Onfarma Medical, Samsun, Turkey) and ranitidine (Ulcuran $50 \mathrm{mg}$, Yavuz Medical,Istanbul, Turkey) 30 minutes prior to the surgical procedure. An 8-hour fasting period was ensured for the patients.

Monitoring was carried out routinely by electrocardiography (ECG), pulse oximetry (peripheral oxygen saturation, $\mathrm{SpO}_{2}$ ) and non-invasive blood pressure (NIBP). A Datex-Ohmeda S/5 Avance (General Electric Inc, Madison, WI, USA) was used. Forehead temperature probes were employed to evaluate the patients' temperature. Following the provision of a safe and effective airway, SADs and ETTs were connected to the breathing system (Primus, Drager, Lubek, Germany). The same anesthesia machine was used to evaluate lung mechanics. Oropharyngeal leak pressures (OLPs) were evaluated by a fixed gas flow of $4 \mathrm{~L} \mathrm{~min}^{-1}$ and closing the circuit's adjustable pressure limiting (APL) valve 5 mins after the airway was secured. Then, the highest anesthesia circuit pressure at which the leak around the seal of the SADs had developed was noted and defined as OLP. Throughout the operation, fluid convection heating pads on table tops and air convection heating above the patients were used to maintain the body temperature at $36-36.5^{\circ} \mathrm{C}$. Anesthesia was induced with propofol (Propofol 1\%, Fresenius ${ }^{\circ}$ Fresenius Kabi Medicine, Istanbul, Turkey; $2 \mathrm{mg} \mathrm{kg}^{-1}$ ), fentanyl (Fentanyl $0.05 \mathrm{mg} / \mathrm{ml}$, Johnson and Johnson 
Medicine, Istanbul, Turkey; $1 \mu \mathrm{g} \mathrm{kg}^{-1}$ ) and rocuronium (Curon ${ }^{\odot} 50 \mathrm{mg} / 5 \mathrm{ml}$ Mustafa Nevzat, Istanbul, Turkey; $0.25 \mathrm{mg} \mathrm{kg}^{-1}$ ) for the patients in the AuraGain and i-Gel ${ }^{\oplus}$ groups. The patients received a rocuronium dose of $0.6 \mathrm{mg} \mathrm{kg}^{-1}$ in the ETT group, which is the 2 $\times$ ED95 dose (the amount of neuromuscular blocking drug required to reduce twitch height by $95 \%$ ) required for endotracheal intubation.

Anesthesia was maintained with 1 minimal alveolar concentration (MAC) of sevoflurane (Sevorane ${ }^{\oplus}$, Liquid $100 \%$, Queenborough, UK; 2\%) with 40\% oxygen in air. Volume-controlled mechanical ventilation was used for all the groups, and the ventilation parameters were set as a tidal volume of $6 \mathrm{ml} \mathrm{kg}$, at a rate of 10-12 $\mathrm{min}^{-1}$, and adjusted as required to maintain an end-tidal carbon dioxide $\left(\mathrm{EtCO}_{2}\right)$ of $30-45 \mathrm{~mm} \mathrm{Hg}$. The high initial fresh gas flow rate $\left(6 \mathrm{~L} \mathrm{~min}^{-1}\right)$ was reduced to $4 \mathrm{~L} \mathrm{~min}^{-1}$.

Following the initiation of spontaneous breathing in all the groups, neostigmine (Neostigmine, Adeka Samsun, Turkey) (0.04 mg kg-1 IV) was used for antagonizing the neuromuscular blockade. Atropine (Atropine Sulphate, Galen Medical, Istanbul,Turkey, $0.02 \mathrm{mg} \mathrm{kg}^{-1} \mathrm{IV}$ ) was given to prevent muscarinic side effects. At the end of the operation, inhalation anesthesia was discontinued, and the SADs or ETT was removed. Postoperative analgesia was provided with tenoxicam (Oksamen 20 mg IV, Mustafa Nevzat, Istanbul, Tukey) and tramadol (Contramal $100 \mathrm{mg}$, Abdi Ibrahim, Istanbul, Turkey, $10 \mathrm{mg} \mathrm{kg}^{-1}$ ).

The appropriate SAD size was chosen according to the manufacturer's user guidelines and patient's body weight. A clear water-based gel was used for lubrication, and SADs were placed with the classical recommended technique and followed by an anesthesia specialist. The AuraGain (AuraGain group) and $\mathrm{i}-\mathrm{Gel}^{\oplus}$ (i-Gel ${ }^{\oplus}$ group) were inserted in supine position, with the patient's head on a standard gel pillow. The insertion was verified with the manual ventilation of the patient and $\mathrm{EtCO}_{2}$ waveform. A 14- or 16-Fr orogastric drainage tube was placed through the drainage tube of the SADs following lubrication. An endotracheal tube with an $8.5-\mathrm{mm}$ internal diameter (ID) for males and 7.5-mm ID for females was chosen. Following intubation, an orogastric tube was inserted. The orogastric tubes were aspirated and then allowed to drain freely.

In all the groups, the patients' heart rate (HR), systolic arterial pressure (SAP), diastolic arterial pressure (DAP), $\mathrm{SpO}_{2}, \mathrm{EtCO}_{2}$, peak airway pressure (Paw) and OLPs were recorded. The measurement periods were determined as follows: preoperatively (T0), following insertion of the airway device (T1), before abdominal carbon dioxide insufflation (T2), just after the insufflation (T3), and every 10 mins after the insufflation (T4-5). Moreover, the insertion procedure duration, insertion attempts, and complications related to the airway devices were recorded.

After the induction of anesthesia and surgical preparation, in the supine position, pneumoperitoneum was created using a Veress needle to $8-10 \mathrm{~mm} \mathrm{Hg}$ of pressure and maintained at this level. Then, the operating table was positioned such that the patient's head was $30^{\circ}$ from the horizontal line in reverse Trendelenburg position, and the cholecystectomy was performed.

Kolmogorov-Smirnov/Shapiro-Wilk test analytical methods was used to determine whether the variables were normally distributed, also investigations were made by using visual methods (histograms, probability plots). Continuous variables were emitted as mean \pm $\mathrm{SD}$ and minimum-maximum values, while numbers and percentages were used to define categorical variables in results. To compare all the variables in the 3 groups the Kruskal-Wallis test was used. Furthermore, MannWhitney $U$ test was performed for continuous variables. For categorical variables Chi-square/Fisher exact test were carried out to test the significance of pairwise differences using Bonferroni correction to adjust for multiple comparisons. Repeated-measures analysis of variance was used to evaluate the changes in HR, SAP, DAP, Paw, $\mathrm{SpO}_{2}$ and $\mathrm{EtCO}_{2}$ by time among the groups. Greenhouse-Geisser correction was provided when the sphericity assumption was disrupted. An overall p-value $<0.05$ was considered statistically significant. The SPSS statistical software package (SPSS for Windows 15.0, Inc., Chicago, IL, USA) was used for all statistical analyses.

For acquiring $80 \%$ power with a $5 \%$ type I error, the research need to include 90 patients (30 for each group). This would allow it to achieve level of minimum clinical significance of the group averages with an impact size of $0.3(\mathrm{f}=0.3)$.

Results. The study was conducted on 114 patients, of which, 9 did not complete the study (3 in the i-Gel ${ }^{\circ}$ and 6 in the ETT groups) due to the conversion to open surgery. Of the recruited patients, 105 completed the study successfully, and the analysis was carried out on them. The AuraGain groups consisted of 38, i-Gel ${ }^{\oplus}$ 35 , and ETT 32 patients. Fifty-six patients were male $(53.3 \%)$, while the rest were female. The average age of the patients was $45.4 \pm 13.7$ years.

There was no difference among the 3 groups in terms of age, gender distribution, ASA physical status, 
anesthesia duration, weight or height. The patients' demographic data are presented in Table 1.

Insertion procedure duration for SADs for AuraGain, $\mathrm{i}-\mathrm{Gel}^{\oplus}$ and ETT was insignificant among the groups ( $p=056$, Table 2). Attempts for insertion for AuraGain, $\mathrm{i}-\mathrm{Gel}^{\oplus}$, and ETT groups was not significant among the groups ( $p=0.854$, Table 2$)$. The first insertion success rates for the groups AuraGain, $\mathrm{i}-\mathrm{Gel}^{\oplus}$ and ETT were not statistically significant between the groups ( $p=0.876$, Table 2). Oropharyngeal leak pressures were compared between SADs group only, not evaluated in ETT group and OLPs were not statistically significant $(p=0.944$, Table 2). Complications related to the airway devices were similar between the groups, $(p=0.992$, Table 2). One patient in the AuraGain and one in the $\mathrm{i}-\mathrm{Gel}^{\bullet}$ group had blood stained SADs observed at the removal. One patient in the ETT group suffered laryngospasm, which was effectively terminated by moderate positive pressure ventilation with $100 \% \mathrm{O}_{2}$. No other complications were encountered. The ease of insertion was carried out according to 2 parameters, the first was the time taken for placement and the second was attempts made for placement. When a SAD was placed under 15 seconds this was classified as straight forward, over 15 seconds was classified as slightly difficult. If the SADs or ETT was not placed at first attempt, it was classified as obviously difficult. There is a significant result among the groups in terms of ease of insertion and in this regard $\mathrm{i}-\mathrm{Gel}^{\circ}$ was favorable (Table 2, $p=0.037$ ).

Heart rate was lower in AuraGain and i-Gel ${ }^{\bullet}$ groups at T1 compared with ETT and the difference was statistically significant $(p<0.017$, Figure 1$)$. And the heart rate alterations were statistically significant among the groups ( $p=0.034$, Figure 1$)$.

The SAP and DAP values were lower at T0, T1, and T2 in the AuraGain group, whereas they were lower at $\mathrm{T} 1$ and $\mathrm{T} 2$ in the $\mathrm{i}-\mathrm{Gel}^{\odot}$ group compared with the ETT group. The difference was statistically significant (Figure 2; $p<0.017$ ).

The patients' peak airway pressure alteration graph is demonstrated in Figure 3. The airway pressures in the AuraGain and $\mathrm{i}-\mathrm{Gel}^{\bullet}$ groups were lower compared

Table 1 - Demographic data of the patients and duration of anesthesia.

\begin{tabular}{|c|c|c|c|c|}
\hline \multirow[t]{2}{*}{ Demographic data } & \multicolumn{4}{|c|}{ Groups } \\
\hline & $\begin{array}{c}\text { AuraGain } \\
(\mathrm{n}=38)\end{array}$ & $\begin{array}{l}\mathrm{i}-\mathrm{Gel}^{\oplus} \\
(\mathrm{n}=35)\end{array}$ & $\begin{array}{l}\text { ETT } \\
(n=32)\end{array}$ & $P$-value \\
\hline Age (years) & $42.68 \pm 14.12$ & $44.86 \pm 13.76$ & $49.25 \pm 12.49$ & 0.131 \\
\hline Gender $(\mathrm{M} / \mathrm{L})$ & $17 / 21$ & $15 / 20$ & $17 / 15$ & 0.436 \\
\hline $\operatorname{ASA}(1 / 2)$ & $20 / 18$ & $22 / 13$ & $17 / 15$ & 0.622 \\
\hline Height $(\mathrm{cm})$ & $163.61 \pm 5.41$ & $161.53 \pm 5.27$ & $162.11 \pm 6.55$ & 0.337 \\
\hline Weight (kg) & $69.27 \pm 6.92$ & $67.91 \pm 10.92$ & $73.10 \pm 9.16$ & 0.076 \\
\hline Duration of anesthesia (min) & $50.79 \pm 9.69$ & $48.20 \pm 11.96$ & $48.97 \pm 11.62$ & 0.630 \\
\hline
\end{tabular}

Table 2 - Insertion procedure durations, attempts, first attempt success rates, ease of insertion, oropharyngeal leak pressures and complication rates for supraglottic airway devices and endotracheal tube groups.

\begin{tabular}{|c|c|c|c|c|}
\hline \multirow[t]{2}{*}{ Procedure } & \multicolumn{4}{|c|}{ Groups } \\
\hline & $\begin{array}{l}\text { AuraGain } \\
(\mathrm{n}=38)\end{array}$ & $\begin{array}{l}\mathrm{i}^{\mathrm{i}-\mathrm{Gel}^{\oplus}} \\
(\mathrm{n}=35)\end{array}$ & $\begin{array}{c}\text { ETT } \\
(n=32)\end{array}$ & $P$-value \\
\hline Insertion procedure duration $(\mathrm{sec})$ & $14.92 \pm 4.27$ & $12.94 \pm 4.60$ & $16.56 \pm 7.31$ & 0.056 \\
\hline Attempts (times) & $1.05 \pm 0.23$ & $1.09 \pm 0.28$ & $1.09 \pm 0.39$ & 0.854 \\
\hline First insertion success rate (\%) & $38 / 38(100)$ & $35 / 35(100)$ & $31 / 32(96.9)$ & 0.876 \\
\hline $\begin{array}{l}\text { Ease of insertion (\%) } \\
\text { Straight forward }(15 \mathrm{sec}) \\
\text { Slightly difficult }(>15 \mathrm{sec}) \\
\text { Obviously difficult }(2 \mathrm{nd} \text { attempt })\end{array}$ & $\begin{array}{c}19(50.0) \\
19(50.0) \\
-\end{array}$ & $\begin{array}{c}27(77.1) \\
8(22.8) \\
-\end{array}$ & $\begin{array}{c}16(50.0) \\
16(50.0) \\
1(3.1)\end{array}$ & $0.037^{*}$ \\
\hline The oropharyngeal leak pressures & $24.92 \pm 3.56$ & $26.72 \pm 4.20$ & - & 0.944 \\
\hline Complications & $1 / 38$ & $1 / 32$ & $1 / 35$ & 0.992 \\
\hline
\end{tabular}


with that of the ETT group, and the difference was statistically significant for each measurement time, $p<0.017$. There were no differences between the groups regarding the increase rates of peak airway pressures, that is, throughout T1-T5. Note that the pressure recordings were taken after the SAD/ETT placement, that is, starting from $\mathrm{T} 1$.

Peak airway pressure alteration graph of the patients is demonstrated in Figure 3. The airway pressures in the AuraGain and $\mathrm{i}-\mathrm{Gel}^{\oplus}$ groups were lower compared with the ETT group, and the difference was statistically significant for each measurement time. There were no differences between the groups regarding the increase rates of peak airway pressures (throughout T1-T5). Note that the pressure recordings were performed after the SAD/ETT placement (starting from T1).

No difference was observed between the groups regarding $\mathrm{SpO}_{2}$ and $\mathrm{EtCO}_{2}$ levels, but there was a different T4 SpO2 value between the AuraGain and $\mathrm{i}-\mathrm{Gel}^{\oplus}$ groups $(p=0.03$, Table 3$)$. Although this was statistically significant, it was clinically insignificant.

Table 3 shows the peripheral oxygen saturation and end-tidal carbon dioxide values of the patients.

Discussion. This is the first study to evaluate the use of AuraGain in LC. The main finding of this study was that both AuraGain and $\mathrm{i}-\mathrm{Gel}^{\bullet} \mathrm{SADs}$ are as successful airway devices as endotracheal intubation is for LC regarding their ease of insertion, first attempt success rates, OLPs and perioperative complications. When ease of insertion was evaluated, the i-Gel ${ }^{\circ}$ seems favorable overall, but in a detailed examination

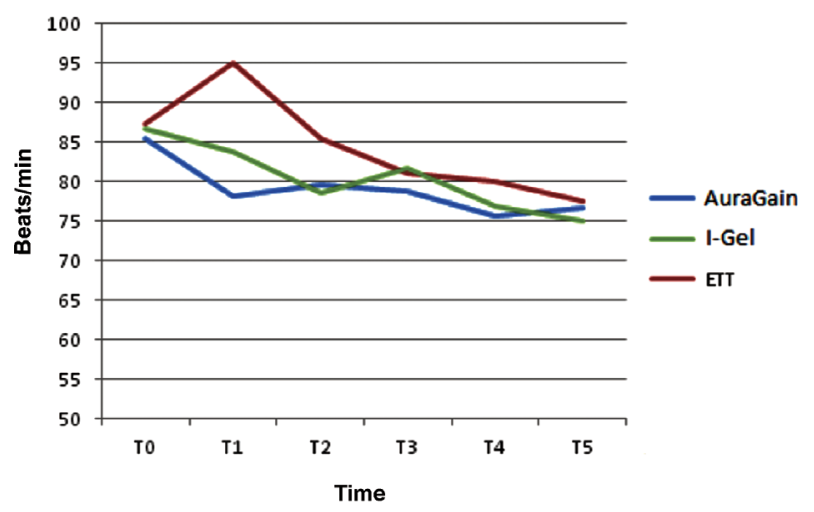

Figure 1 - Heart rate alteration graph of the patients in groups AuraGain, i-Gel ${ }^{\circ}$, and ETT. $P<0.017$ for T1 (both AuraGain and i-Gel ${ }^{\circ}$ compared with ETT). T0 - time period, preoperatively, $\mathrm{T} 1$ - the time following insertion of the airway device, T2 - the time before abdominal carbon dioxide insufflations T3 the time just after the insufflation T4, T5 - the times every 10 mins after the insufflation, ETT - endotracheal intubation of results, first attempt rates of both SADs are more successful than ETT. Even the placement of AuraGain and $\mathrm{i}-\mathrm{Gel}^{\odot}$ is just over 15 seconds, their first attempt success rate $100 \%$. Also, the time needed for placement of $\mathrm{i}-\mathrm{Gel}^{\oplus}$ is much less than AuraGain and ETT. The placement of AuraGain takes 2 or 3 secs more than i-Gel ${ }^{\oplus}$ which can be a result of that $\mathrm{i}-\mathrm{Gel}^{\oplus}$ does not need cuff inflation. In overall evaluation median time

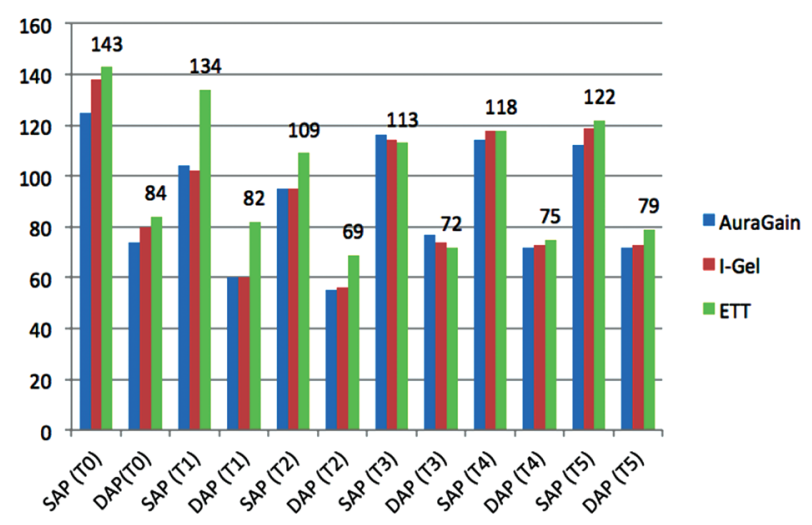

Figure 2 - Mean systolic and diastolic arterial pressure alteration graph of the patients in groups AuraGain, $\mathrm{i}-\mathrm{Gel}^{\circ}$, and ETT. $P<0.017$ at T0, T1 and T2 for AuraGain compared with ETT; $P<0.017$ at T1 and T2 for $\mathrm{i}-\mathrm{Gel}^{\circ}$ compared with ETT. T0 - time period, preoperatively, $\mathrm{T} 1$ - the time following insertion of the airway device, T2 - the time before abdominal carbon dioxide insufflations T3 - the time just after the insufflation $\mathrm{T} 4$, T5 - the times every 10 mins after the insufflation. SAP - systolic arterial pressure, DAP - diastolic arterial pressure, ETT - endotracheal intubation

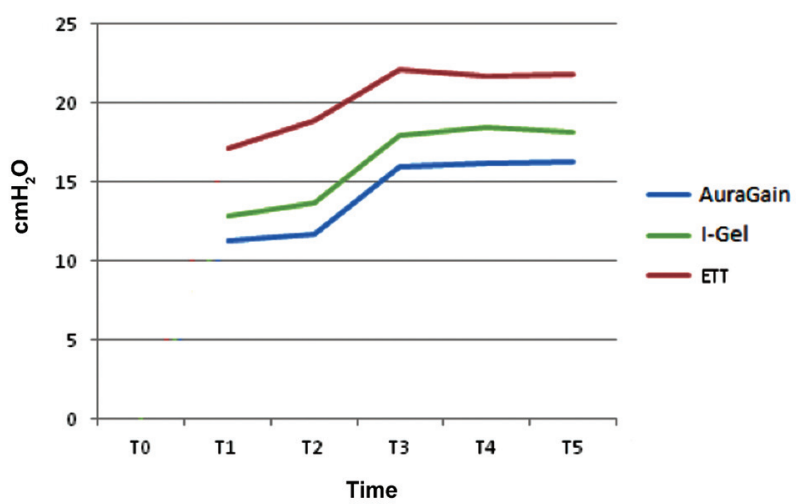

Figure 3 - Peak airway pressure alteration graph of the patients in groups AuraGain, $\mathrm{i}-\mathrm{Gel}^{\circ}$ and ETT in time. $\mathrm{P}<0.017$ for all times (both AuraGain and $\mathrm{i}-\mathrm{Gel}^{\circ}$ compared with ETT). T0 - time period, preoperatively, T1 - the time following insertion of the airway device, T2 - the time before abdominal carbon dioxide insufflations T3 - the time just after the insufflation T4, T5 - the times every 10 mins after the insufflation, ETT endotracheal intubation 
Table 3 - Peripheral oxygen saturation and end-tidal carbon dioxide values of the patients.

\begin{tabular}{|c|c|c|c|c|}
\hline \multirow{2}{*}{$\begin{array}{l}\text { Peripheral oxygen } \\
\text { saturation }\end{array}$} & \multicolumn{4}{|c|}{ Groups } \\
\hline & $\begin{array}{c}\text { AuraGain } \\
(\mathrm{n}=38)\end{array}$ & $\begin{array}{l}\mathrm{i}^{\mathrm{i}-\mathrm{Gel}^{\bullet}} \\
(\mathrm{n}=35)\end{array}$ & $\begin{array}{c}\text { ETT } \\
(n=32)\end{array}$ & $P$-value \\
\hline $\mathrm{SpO}_{2}\left(\mathrm{~T}_{0}\right)$ & $99.21 \pm 1.12$ & $98.54 \pm 1.42$ & $98.78 \pm 1.10$ & 0.051 \\
\hline $\mathrm{SpO}_{2}\left(\mathrm{~T}_{1}\right)$ & $99.87 \pm 0.34$ & $99.83 \pm 0.45$ & $99.84 \pm 0.37$ & 0.957 \\
\hline $\mathrm{EtCO}_{2}\left(\mathrm{~T}_{1}\right)$ & $32.42 \pm 3.30$ & $32.14 \pm 2.79$ & $31.69 \pm 4.18$ & 0.861 \\
\hline $\mathrm{SpO}_{2}\left(\mathrm{~T}_{2}\right)$ & $99.66 \pm 0.71$ & $99.71 \pm 0.62$ & $99.66 \pm 0.75$ & 0.983 \\
\hline $\mathrm{EtCO}_{2}\left(\mathrm{~T}_{2}\right)$ & $31.00 \pm 2.11$ & $31.20 \pm 2.64$ & $31.41 \pm 3.44$ & 0.818 \\
\hline $\mathrm{SpO}_{2}\left(\mathrm{~T}_{3}\right)$ & $99.53 \pm 0.80$ & $99.57 \pm 0.81$ & $99.53 \pm 0.80$ & 0.851 \\
\hline $\mathrm{EtCO}_{2}\left(\mathrm{~T}_{3}\right)$ & $31.58 \pm 2.06$ & $30.71 \pm 2.55$ & $31.94 \pm 3.39$ & 0.057 \\
\hline $\mathrm{SpO}_{2}\left(\mathrm{~T}_{4}\right)^{3}$ & $99.66 \pm 0.67$ & $99.17 \pm 0.92$ & $99.50 \pm 0.67$ & $0.030^{*}$ \\
\hline $\mathrm{EtCO}_{2}\left(\mathrm{~T}_{4}\right)$ & $33.11 \pm 2.18$ & $32.38 \pm 3.36$ & $32.09 \pm 3.15$ & 0.471 \\
\hline $\mathrm{SpO}_{2}\left(\mathrm{~T}_{5}\right)^{4}$ & $99.66 \pm 0.78$ & $99.56 \pm 0.66$ & $99.44 \pm 0.76$ & 0.223 \\
\hline $\mathrm{EtCO}_{2}\left(\mathrm{~T}_{5}\right)$ & $33.82 \pm 2.31$ & $33.26 \pm 3.26$ & $32.50 \pm 2.62$ & 0.219 \\
\hline \multicolumn{5}{|c|}{$\begin{array}{l}\text { Values are presented as mean } \pm \mathrm{SD} \text {. } \\
\text { heral oxygen saturation, EtCO } \mathrm{CO}_{2} \text { - end-tidal carbon dioxide, } \\
\text { operatively, T1 - the time following insertion of the airway device, } \\
\text { abdominal carbon dioxide insufflations, T3 - the time just after the } \\
\text { i T4, T5 - the times every } 10 \text { mins after the insufflation } \\
<0.05 \text { (difference between AuraGain and i-Gel }{ }^{\circ} \text { ) }\end{array}$} \\
\hline
\end{tabular}

taken to placement of devices is the shortest in i-Gel ${ }^{\circ}$ group, the longest in ETT group but the difference is not significant statistically. In this regard, our finding are compatible with the previous findings. ${ }^{5,6}$

In laparoscopic surgery, pneumoperitoneum can increase the airway pressure. ${ }^{1}$ During the insufflation, our patients' peak airway pressures increased in all the groups, and the difference was significant compared with the basal values. However, the rates of increment were not significantly different between the groups. The peak airway pressures throughout the operation were lower in the patients in whom AuraGain and i-Gel ${ }^{\bullet}$ were used, compared with endotracheal intubation. When the AuraGain and i-Gel ${ }^{\oplus}$ groups were compared regarding their Paws, although there was no significant difference between the groups, we observed that the Paws in the AuraGain group were relatively lower. This may have been related to ID differences of SADs. The AuraGain number 4 LMA has a relatively wider airway tube when compared with i-Gel ${ }^{\oplus}$. (The AuraGain and i-Gel ${ }^{\oplus}$ IDs are 12.7 and $12.3 \mathrm{~mm}$, respectively). Moreover, AuraGain has an anatomically curved shape and a wider tube, and it is more flexible to fit. In the literature, there were no data comparing $\mathrm{i}-\mathrm{Gel}^{\odot}$ and AuraGain, but Jaganattan et $\mathrm{al}^{7}$ compared the Supreme ${ }^{\mathrm{TM}}$ and AuraGain LMAs regarding their application ease, time and success rates, gastric tube insertion, fibreoptic grades of view, airway quality and complications in pediatric patients. They suggested that AuraGain was easier to insert, and more importantly, provided stability in the airway because it needs few airway maneuver compared with the Supreme LMA.
During laparoscopic surgeries, the risk of passive regurgitation from the stomach increases due to the gastric insufflation. ${ }^{1}$ However, previous studies have shown that even the use of classical LMA or ProSeal LMA did not increase the risk of passive regurgitation or gastric aspiration. ${ }^{8}$ The 'rule of 15 ' was defined to avoid regurgitation while using a SAD for laparoscopicsurgeries (Trendelenburg tilt $<15$ degree; peritoneal insufflation $<15 \mathrm{~cm} \mathrm{H}_{2} \mathrm{O}$; and duration of abdominal insufflation $<15$ minutes). ${ }^{9}$ All our insufflations were performed in supine position with an abdominal insufflation pressure of $8-10 \mathrm{~mm} \mathrm{Hg}$, and all the procedures were completed in reverse Trendelenburg position. These may be reasons why no aspiration complications were observed in our patients. In concordance with our findings, Park et al ${ }^{10}$ could not find any difference between SADs and ETTs regarding regurgitation and they did not observe any regurgitation cases in their research. Also, they did not find any difference between several SADs and ETTs, with respect to the rate of insertion success on the first attempt, and insertion time and OLP in patients undergoing laparoscopic surgery. In the perioperative period, the adverse events in the 3 groups were not significantly different. In the ETT group, one patient had laryngospasm following extubation and was treated with positive pressure ventilation with $100 \% \mathrm{O}_{2}$. Moreover, one patient in each SAD group had minor soft tissue damage. No complications were observed during the postoperative period. Park et $\mathrm{al}^{10}$ observed the incidences of laryngospasm, cough at removal, dysphagia or dysphonia, sore throat, and hoarseness were higher in the ETT group than in the SADs 
group. Other complications showed no evidence of any difference between the SADs and ETT groups. We observed the same complication rates in our groups.

Our secondary outcome was the devices' effects on hemodynamic responses during the procedure. The results demonstrated that the $\mathrm{HR}, \mathrm{SAP}$, and DAP values increased significantly following the insertion of ETT, while there were no clinically important changes in either SAD group. Responses to laryngoscopy and ET intubation are related to increased sympathetic reflex and sympathoadrenal activity. ${ }^{11}$ The glossopharyngeal and vagus nerves create hemodynamic responses to laryngoscopy and intubation, as well as the laryngospasm reflex. ${ }^{12}$ The irritation caused in the supraglottic area and cuff inflation in the trachea are the major causes of hemodynamic response during intubation. ${ }^{12}$ Moreover, the intensity of the response is related to the intensity of the stimuli applied to the base of the tongue. ${ }^{13}$ Hemodynamic changes such as tachycardia, hypertension, and arrhythmias during laryngoscopy and intubation can be tolerated well in the patients without comorbidity. However, they can cause serious complications in patients with coexisting cardio- or cerebrovascular diseases. ${ }^{14}$ When Anjan Das et $\mathrm{al}^{15}$ compared the hemodynamic changes between the Pro-Seal LMA and $\mathrm{i}-\mathrm{Gel}^{\circ}$ during the day case surgery, there was significant rise in pulse rate and mean blood pressure during insertion with use of PLMA when compared to i-Gel ${ }^{\oplus}$. In our study, when the $\mathrm{i}-\mathrm{Gel}^{\circledR}$ and AuraGain SADs were compared regarding their hemodynamic changes, although they had different structures and materials, there were no significant differences between the groups. However, in the intubated patients, there were significant increases in the hemodynamic parameters. Although i-Gel has been previously compared to ETT and other SADs regarding hemodynamic changes, our study is the first which compares the AuraGain with ETT and i-Gel ${ }^{\oplus}{ }^{16}$

A limitation of this research was the different rocuronium dosages. The rocuronium dose applied to the ETT group was the $2 \times$ ED95 dose required for endotracheal intubation. Smaller doses of rocuronium were applied to the AuraGain and $\mathrm{i}-\mathrm{Gel}^{\bullet}$ groups. This may have affected the patients' Paws and hemodynamics, but these potential effects were not observed. In addition, in similar studies in the literature, rocuronium was applied with the same doses in each group. ${ }^{7}$ However, the reduced doses of muscle relaxants given to the SAD groups may have been an advantage in this research. Another limitation was that the fentanyl dosage may not have been sufficient to prevent hemodynamic changes in the ETT group. Fentanyl at $1 \mu \mathrm{g} \mathrm{\textrm {kg } ^ { - 1 }}$ was used in all groups, but Hosalli et al ${ }^{17}$ compared both $3 \mu \mathrm{g} \mathrm{kg}^{-1}$ and $5 \mu \mathrm{g} \mathrm{kg}^{-1}$ of fentanyl to prevent hemodynamic responses; they concluded that both the 3 and $5 \mu \mathrm{gg}^{-1}$ doses prevented a response, but $5 \mu \mathrm{g} \mathrm{kg}^{-1}$ of fentanyl completely abolished the hemodynamic responses. In this study, larger doses should have been used to prevent hemodynamic responses in the ETT group.

In conclusion, both AuraGain and $\mathrm{i}-\mathrm{Gel}^{\oplus} \mathrm{SADs}$ are comparable to ETT used for airway control in general anaesthesia for LC regarding application ease, insertion duration and perioperative complications. Both SADs are convenient and usable alternatives to ETT and i- $\mathrm{Gel}^{\oplus}$ is the easiest one to insert. Favorable hemodynamic responses to AuraGain and $\mathrm{i}-\mathrm{Gel}^{\bullet} \mathrm{SADs}$ may mean that they are superior to ETT.

Acknowledgment. We would like to thank Scribendi for English language editing.

\section{References}

1. Almeida G, Cost AC, Machado HS. Supraglottic airway devices: A review in a new era of airway management. $J$ Anesth Clin Res 2016; 647: 2-9.

2. Ramaiah R, Das D, Bhananker S, Joffe A. Extraglottic airway devices: a review. Int J Crit Illn Inj Sci 2014; 4: 77-87.

3. Parikh S, Parekh S, Doshi C, Vyas V. Proseal laryngeal mask airway versus cuffed endotracheal tube for laparoscopic surgical procedures under general anesthesia: a random comparative study. Anesth Essays Res 2017; 11: 958-963.

4. Lai CJ, Liu CM, Wu CY, Tsai FF, Tseng PH, Fan SZ. i-Gel ${ }^{\circledast}$ is a suitable alternative to endotracheal tubes in the laparoscopic pneumoperitoneum and trendelenburg position. BMC Anesthesiol 2017; 17: 1-7.

5. Shariffuddin II, Teoh WH, Tang E, Hashim N, Loh PS. Ambu ${ }^{\oplus}$ Auragain $^{\mathrm{TM}}$ Versus Lma Supreme ${ }^{\mathrm{TM}}$ Second Seal ${ }^{\mathrm{TM}}$ : A randomised controlled trial comparing oropharyngeal leak pressures and gastric drain functionality in spontaneously breathing patients. Anaesth Intensive Care 2017: 45: 244-250.

6. Yahaya Z, Teoh W, Dintan N, Agrawal R. The Ambu ${ }^{\circledR}$ Aura-I ${ }^{\mathrm{TM}}$ laryngeal mask and lma supreme ${ }^{\mathrm{TM}}$ : A randomized trial of clinical performance and fibreoptic positioning in unparalysed, anaesthetised patients by novices. Anesthesiol Res Pract 2016: $1-8$.

7. Jagannathan N, Hajduk J, Sohn L, Huang A, Sawardekar A, Gebhardt ER, et al. A randomised comparison of the Ambu ${ }^{\circ}$ Auragain $^{\mathrm{TM}}$ And The Lma ${ }^{\circledast}$ supreme in infants and children. Anaesthesia 2016; 71: 205-212.

8. Najeeb R, Saini H, Ommid M, Asma A. Comparison of i-Gel ${ }^{\oplus}$, Pro-Seal LMA and endotracheal tube in laparascopic surgeries. IOSR Journal of Dental and Medical Sciences 2015; 14: 36-40.

9. Lemos J, De Oliveira GJ, De Pereira CH, Lemos L, De Carvalho L, Módolo N. Gastric regurgitation in patients undergoing gynecological laparoscopy with a laryngeal mask airway: A prospective observational study. J Clin Anesth 2017; 36: 32-35. 
10. Park S, Ko G, Choi G, Ahn E, Kang H. Comparison between supraglottic airway devices and endotracheal tubes in patients undergoing laparoscopic surgery: A systematic review and metaanalysis. Medicine 2016; 95: 1-8.

11. Vaidyanathan R, Anand A Comparative study of haemodynamic responses between endotracheal intubation and Lma insertion. J Evolution Med Dent Sci 2016; 5: 466-471.

12. Song ZL, Yue SY, Chen YY, Zhao XM. Comparison of oropharyngeal airway cap and tracheal intubation on systemic stress responses and hemodynamic parameters in pediatric laparoscopic procedures. Int J Clin Exp Med 2017; 10: 7973-7980.

13. Roshith T, Rahaman H, Padmanabh S. Prospective comparative study of haemodynamic changes during insertion of laryngeal mask airway versus endotracheal tube in paediatric patients. Journal of Evidence Based Medicine and Healthcare 2016: 2435-2438.
14. Imam M. Comparison of Air- $Q^{\circledR}$ masked laryngeal airway and standard endotracheal tube during gynecological laparoscopic surgery. J Anesth Clin Res 2015: 6-12.

15. Das A, Majumdar S, Mukherjee A, Mitra T, Kundu R, Hajra $\mathrm{BK}$, et al. $\mathrm{i}-\mathrm{Gel}^{\oplus}$ In ambulatory surgery: A comparison with Lma-Proseal $^{\mathrm{TM}}$ in paralyzed anaesthetized patients. J Clin Diagn Res 2014; 8: 80-84.

16. Agarwal P, Kumar D. Comparison of clinical performance and hemodynamic changes of i-Gel ${ }^{\oplus}$ with Lma-Prosealtm in elective surgeries. Iosr Journal of Dental and Medical Sciences 2015; 14 : $9-12$.

17. Hosalli V, Es A, Hulkund S, Joshi C. Comparative efficacy of different doses of fentanyl on cardiovascular responses to laryngoscopy and tracheal intubation. J Clin Diagn Res 2014: 1-3. 